\title{
Density Functional Theory Study of Oxygen Migration in Molten
}

\author{
Carbonate \\ Xueling Lei ${ }^{\mathrm{a}, \mathrm{b}}$, Kahla Haines ${ }^{\mathrm{b}}$, Kevin Huang ${ }^{\mathrm{c}}$, Changyong Qin ${ }^{\mathrm{b}, 1}$ \\ ${ }^{a}$ Department of Physics, Jiangxi Normal University, Nanchang, Jiangxi 330022, China \\ ${ }^{\mathrm{b}}$ Department of Biology, Chemistry and Environmental Health Science, Benedict College, \\ Columbia, South Carolina 29204, USA \\ c Department of Mechanical Engineering, University of South Carolina, Columbia, South \\ Carolina 29207, USA
}

\begin{abstract}
The process of oxygen migration in alkali molten carbonate salts has been examined using density functional theory method. All geometries were optimized at the B3LYP/6-31G(d) level, while single point energy corrections were performed using MP4 and CCSD(T). At TS, a O-O-O linkage is formed and O-O bond forming and breaking is concerted. A cooperative "cogwheel" mechanism as described in the equation of $\mathrm{CO}_{4}{ }^{2-}+\mathrm{CO}_{3}{ }^{2-} \rightarrow \mathrm{CO}_{3}{ }^{2-} \cdots \mathrm{O} \cdots \mathrm{CO}_{3}{ }^{2-} \rightarrow \mathrm{CO}_{3}{ }^{2-}+\mathrm{CO}_{4}{ }^{2-}$ is involved. The energy barrier is calculated to be 103.0, 136.3 and $127.9 \mathrm{~kJ} / \mathrm{mol}$ through an intra-carbonate pathway in lithium, sodium and potasium carbonate, respectively. The reliability and accuracy of B3LYP/6-31G(d) were confrmed by $\operatorname{CCSD}(\mathrm{T})$. The calculated low values of activation energy indicate that the oxygen transfer in molten carbonate salts is fairly easy. In addition, it is found that lithium carbonate is not only a favorable molten carbonate salt for better cathode kinetics, but also it is widely used for reducing the melting point of $\mathrm{Li} / \mathrm{Na}$ and $\mathrm{Li} / \mathrm{K}$ eutectic $\mathrm{MC}$ mixtures. The current results imply that the process of oxygen reduction in MC modified cathodes is facilitated by the presence of $\mathrm{MC}$, resulting in an enhancement of cell performance at low operating temperatures.
\end{abstract}

Keywords: Solid Oxide Fuel Cell; Molten Carbonate; Oxygen Reduction Reaction; Oxygen Migration; Density Functional Theory

\footnotetext{
${ }^{1}$ Corresponding author: Changyong Qin, qinc@ benedict.edu
} 


\section{Introduction}

Solid oxide fuel cells (SOFCs) have received considerable attention for the purpose of clean energy with high efficiency and fuel flexibility [1-3]. However, conventional SOFCs only operate at high temperatures of the range $800-1000{ }^{\circ} \mathrm{C}$, which leads to both technical challenges and high cost in fabrication. Both are main impendence for the commercialization of SOFCs. One of the key solutions to address this issue is to lower the operating temperature under $600{ }^{\circ} \mathrm{C}$, where higher reliability and lower cost can be achieved. Recently, it has been reported that binary or ternary molten carbonate (MC) compositions incorporated into the solid electrolyte or cathode can lower the operating temperature, strengthen mechanical properties, yield high power density, and result in excellent cell performances [4-15]. For example, a samarium doped ceria (SDC) electrolyte with $\left(\mathrm{Li}_{0.52} / \mathrm{Na}_{0.48}\right)_{2} \mathrm{CO}_{3}$ (30 wt.\% loading) was used in SOFCs and the cell reached the maximum power density $\left(\mathrm{P}_{\max }\right)$ of $1704 \mathrm{~mW} \cdot \mathrm{cm}^{-2}$ at $650{ }^{\circ} \mathrm{C}$ [5]. Zhu et al. examined a series of ceria-based two-phase composite electrolyte materials and found ceria/MC composites very competitive for SOFCs operated at $<600{ }^{\circ} \mathrm{C}$ [6-8]. Previous work by Huang et al. [9-11] also indicates that the presence of MC phase in the cathode of SOFC significantly reduces the cathode area specific resistance (ASR) and polarization resistance $\left(\mathrm{R}_{\mathrm{p}}\right)$ by a factor of 10 . This implies that the oxygen reduction reaction (ORR) has been remarkably enhanced and the operating temperature of SOFCs can then be largely reduced. Similarly, Bodén et al. [12] found that the proton conductivity of SDC-Li/Na carbonate composite increases as the content of carbonate salt increases. On the other hand, Xie et al. [13] predicted that a composite electrolyte of $\mathrm{La}_{0.9} \mathrm{Sr}_{0.1} \mathrm{Ga}_{0.8} \mathrm{Mn}_{0.2} \mathrm{O}_{2.85}$ with eutectic carbonate $\left(\mathrm{Li}_{2} \mathrm{CO}_{3}: \mathrm{Na}_{2} \mathrm{CO}_{3}=52: 48\right)$ is a promising candidate for long-term low temperature SOFCs due to its notable thermal stability and fairly high performance.

All the evidences indicate that the presence of a MC phase not only enhances the ionic conductivity, but also improves the kinetics of the ORR process. It is well understood that the ORR process is a crucial step for the cathode of SOFCs. It only occurs at the so-called triple phase boundary (TPB) region as displayed in Fig. 1. TPB is a very small overlap between feeding gas, electrolyte and cathode, acting like a bridge for oxygen ion migration from cathode to electrolyte. Unfortunately, the rate of migration is largely limited by the available surface at TPB. With the presence of MC at TPB, the new micro-MC phase will provide much more surface area than the 
TPB itself for the oxygen ion migration. On the other hand, it will facilitate the adsorption and dissociation of oxygen on the MC treated cathode surface, resulting in better cathode kinetics.

To understand the mechanism of ORR with the presence of MC in fuel cells, both theoretical and experimental efforts have been carried out. Huang et al. proposed a new ORR charge-transfer model involving MC phase [15] and the ORR pathways in the presence of MCs [11]. In our recent work [16], the change of energy is calculated to be $-101.7 \mathrm{~kJ} / \mathrm{mol}$ for the reaction of $\mathrm{CO}_{3}{ }^{2-}+\mathrm{O}_{2} \rightarrow$ $\mathrm{CO}_{5}{ }^{2-}$, indicating that the adsorption of $\mathrm{O}_{2}$ on the $\mathrm{MC}$ surface is thermodynamically favorable. The equilibrium constant of 1.1 at $873 \mathrm{~K}$ for the subsequent reaction of $\mathrm{CO}_{5}{ }^{2-}+\mathrm{CO}_{3}{ }^{2-} \leftrightarrow 2 \mathrm{CO}_{4}{ }^{2-}$ indicates that the $\mathrm{CO}_{4}{ }^{2-}$ is a vital intermediate and oxygen carrier. The existence of $\mathrm{CO}_{4}{ }^{2-}$ is then verified by in-situ Raman spectroscopy [17]. In Ref. [18], the oxygen dissociation reaction in alkali molten carbonate has been systematically studied. The energy barrier is calculated to be $197.9,116.7$, and $170.3 \mathrm{~kJ} / \mathrm{mol}$ in the $\left(\mathrm{M}_{2} \mathrm{CO}_{3}\right)_{4}$ cluster, $\mathrm{M}=\mathrm{Li}, \mathrm{Na}$, and $\mathrm{K}$, respectively. It is very clear that the molten carbonate salt has directly participated in the ORR process and plays an important role as a catalyst in the cathode of SOFCs.

For oxygen migration from the MC surface to MC/cathode interface, Huang et al. [15] proposed a cooperative "cogwheel" mechanism, involving the breaking and reforming of the $\mathrm{O}-\mathrm{CO}_{3}{ }^{2-}$ bond. However, this assumption has not been verified yet by experiments or theoretical simulations. Up to date, only very little information about oxygen transfer in MC has been reported in the literatures. In the current study, we focus mainly on the process of oxygen migration in alkali molten carbonate salts, especially its energetics and pathways. The aim is to provide theoretical foundations for understanding oxygen migration in different molten carbonate salts. The transition states, activation energies and reaction pathways are investigated using density functional theory (DFT) calculations.

\section{Computational Methods}

All calculations were performed in Gaussian09 suite of quantum programs [19]. Local minimum structures were optimized at the B3LYP [20-21]/6-31G(d) [22-25] level. Vibrational frequencies were examined to ensure that the reactant and product structures are local minima while each transition state (TS) is a first-order saddle point on the potential energy surface (PES). Both MP4 [26] and CCSD(T) [27-28] in combination with variable basis sets (6-311G++(d) [29-31], CBSB7 [32], and LANL2DZ [33-34] ) were used to assure the accuracy and reliability of 
the energy values obtained at the B3LYP/6-31G(d) level. In addition, the zero-point energy (ZPE) and Mulliken charges were calculated and discussed.

In order to elucidate the process of oxygen migration in $\mathrm{MC}$, a four-formula cluster $\left(\mathrm{M}_{2} \mathrm{CO}_{3}\right)_{4}$ $(\mathrm{M}=\mathrm{Li}, \mathrm{Na}$, and $\mathrm{K})$, was used as the surrogate of the molten state of alkali carbonate, which is shown in Fig. 2. The structures were optimized at the B3LYP/6-31G (d) level and showed very good agreement with the previous report in Ref. [18]. The structure of each transition state was initially indentified using PES scan method, i.e. the highest energy point on PES. The geometry was then optimized with full relaxation and confirmed to be a saddle point on PES. The intrinsic reaction coordinate (IRC) calculations were used to determine the reaction path.

\section{Results and Discussions}

\subsection{Intramolecular migration of oxygen in carbonate ion}

Fig. 3 shows the structures of beginning, transitioning and ending phase of the intramolecular transfer of oxygen in $\mathrm{CO}_{3}{ }^{2-}$ together with bond distances and relative energies. The reactant and product are identical $\mathrm{CO}_{4}{ }^{2-}$ with a $\mathrm{C}_{\mathrm{s}}$ symmetry, while $\mathrm{O} 5$ is bonded to $\mathrm{O} 4$ and $\mathrm{O} 2$, respectively. Therefore, only the reactant structure is discussed here. Once $\mathrm{O} 5$ is attached to the carbonate and the $\mathrm{O} 5-\mathrm{O} 4$ bond is formed, $\mathrm{C} 1-\mathrm{O} 4$ is weakened with a bond distance of $1.387 \AA$ (Note: the C-O distance in $\mathrm{CO}_{3}{ }^{2-}$ is optimized to be $1.313 \AA$ ). Both $\mathrm{C} 1-\mathrm{O} 2$ and $\mathrm{C} 1-\mathrm{O} 3$ are shortened to $1.263 \AA$ and $1.285 \AA$, respectively. The resonance structure of carbonate unit has been largely weakened. The Mulliken charge on O4-O5 is calculated to be $-1.13 e$ and its bond distance is $1.496 \AA$, both indicating $\mathrm{O} 4-\mathrm{O} 5$ a fragment between superoxide and peroxide. The stretching of O4-O5 leads to a TS on PES. At TS, O5-O4 is $2.304 \AA$ as same as O5-O2, showing that O5-O4 is breaking and O5-O2 is forming along the reaction coordinator. Furthermore, O5 is almost detached from the carbonate at TS, and the bond distance of $\mathrm{C} 1-\mathrm{O} 2, \mathrm{C} 1-\mathrm{O} 3$ and $\mathrm{C} 1-\mathrm{O} 4$ is changed to $1.304,1.299$ and $1.304 \AA$, respectively. The distances are close to $1.313 \AA$ in $\mathrm{CO}_{3}{ }^{2-}$ showing that the resonance structure of carbonate ( $\mathrm{C} 1$ center) is largely recovered. Molecular orbitals related to the interaction between $\mathrm{O} 5$ and carbonate are displayed in Fig. 4. Small overlaps between $2 \mathrm{p}$ of $\mathrm{O} 5$ and $2 \mathrm{p}$ lone pairs of $\mathrm{O} 4$ and $\mathrm{O} 2$ can be observed, but the electron density between either $\mathrm{O} 5$ and $\mathrm{O} 4$ or $\mathrm{O} 5$ and $\mathrm{O} 2$ is not significantly increased due to the long distance between oxygen atoms. Therefore, O5 is almost separated from the carbonate ion at TS. The energy barrier is calculated to be $226.4 \mathrm{~kJ} / \mathrm{mol}$. This energy is relatively high, but still feasible at high temperatures. The intramolecular migration 
of oxygen is only studied in the carbonate ion here. In the next sections, intermolecular processes will be presented in the selected molten carbonate salts.

\subsection{Intermolecular migration of oxygen in lithium carbonate}

For the reaction of oxygen transfer in lithium molten carbonate, three stationary points were located on PES as shown in Fig. 5 together with the relative energies. Those optimized structures correspond to the starting, transition and ending state of the oxygen transfer process. In Fig. 5, the top is an enlarged local structure of $\left[\mathrm{Li}_{2} \mathrm{O}\left(\mathrm{CO}_{3}{ }^{2-}\right)_{2}\right]^{2-}$ where oxygen transfer occurs, while the bottom is the overall cluster of $\mathrm{O}-\left(\mathrm{Li}_{2} \mathrm{CO}_{3}\right)_{4}$. At the beginning, $\mathrm{O} 4$ is bonded to $\mathrm{O} 1$ with $\mathrm{O} 1-\mathrm{O} 4$ distance of $1.465 \AA$. It is noticeable that $\mathrm{CO}_{4}{ }^{2-}$ is not planar in the embedded cluster with an O4-O1-C1-O3 dihedral of 20.0 degrees. However, the bond distances in $\mathrm{CO}_{4}{ }^{2-}$ are close to those in the gas phase (See section 3.1). The charge of O1-O4 is $-0.77 \mathrm{e}$, which is 0.36 e less than the value calculated from a single $\mathrm{CO}_{4}{ }^{2-}$ ion. The calculated total charge of $\mathrm{CO}_{4}{ }^{2-}$ and $\mathrm{CO}_{3}{ }^{2-}$ is -1.030 and -1.011 e, respectively. Both are almost same as the charge of $\mathrm{CO}_{3}{ }^{2-}(0.976 \mathrm{e})$ in the cluster of $\left(\mathrm{Li}_{2} \mathrm{CO}_{3}\right)_{4}$.

The oxygen transfer is initiated by the stretching of O1-O4. At TS (Fig. 5), the O1-O4 bond was elongated to $1.869 \AA$, while O4-O5 shortened to $1.940 \AA$ A, showing a bond breaking and forming process. The resonance in the carbonate $(\mathrm{C} 1$ center) is almost restored after $\mathrm{O} 4$ leaves, indicated by the C1-O1, C1-O2, C1-O3 distance of 1.318, 1.290, $1.282 \AA$, respectively. The IRC calculation proves the connectivity from the reactant to TS and then to the product on PES, indicating a complete process of oxygen migration from one carbonate to another carbonate ion. Molecular orbital analysis shows that the bond forming and breaking process is concerted through the formation of a O1-O4-O5 linkage. Two major bonding modes exist as shown in Fig. 6. One is a sigma bond between the 2p orbiatls of oxygen along the O1-O4-O5 axis and the other is a pi bond by oxygen 2 p. As evidenced by the bond distance of O1-O4 and O4-O5, the formation of this linkage has stabilized the transition structure and may largely lower the energy barrier for the oxygen transfer between two carbonate ions. The energy barrier is actually calculated to be 102.1 $\mathrm{kJ} / \mathrm{mol}$, which is $124.3 \mathrm{~kJ} / \mathrm{mol}$ lower than that of the intramolecular path in Section 3.1.

\subsection{Intermolecular migration of oxygen in sodium carbonate}

In the case of oxygen migration in the sodium carbonate cluster of $\left(\mathrm{Na}_{2} \mathrm{CO}_{3}\right)_{4}$, the optimized strcutures of reactant, transition state, and product, as well as the relative energy are displayed in 
Fig. 7. Similarly, those structures show the process of oxygen $(\mathrm{O} 4)$ transfer from one carbonate ( $\mathrm{C} 1$ center) to another carbonate ion ( $\mathrm{C} 2$ center). In the reactant structure, the bond distance of O4-O1 is $1.480 \AA$ and the carbonate ion $\left(\mathrm{C}_{1}-\mathrm{O}_{1-3}\right)$ acts as a carrier of atomic oxygen (O4). O4 is then leaving toward O5, which leads to a TS on PES. At TS, the O1-O4 and O4-O5 bond is 2.098 and $1.859 \AA$, respectively. The formation of O1-O4-O5 linkage is similar to the transition in $\left(\mathrm{Li}_{2} \mathrm{CO}_{3}\right)_{4}$. The TS structure is connected back to the reactant and forward to the product on PES by the IRC calculations. The activation energy is calculated to be $131.4 \mathrm{~kJ} / \mathrm{mol}$, which is 28.0 $\mathrm{kJ} / \mathrm{mol}$ higher than the barrier in the lithium carbonate, but still $95.0 \mathrm{~kJ} / \mathrm{mol}$ lower than that of the intramolecular path.

\subsection{Intermolecular migration of oxygen in potassium carbonate}

For oxygen migration in the potassium carbonate cluster of $\left(\mathrm{K}_{2} \mathrm{CO}_{3}\right)_{4}$, the structures of reactant, transition state and product are displayed in Fig. 8 along with the relative energies. In the reactant, O1-O4 is $1.465 \AA$ and $3.684 \AA$ for O4-O5. As O4 moves toward O5, the O1-O4 bond starts breaking, while a new $\mathrm{O} 4-\mathrm{O} 5$ bond starts forming. At TS, $\mathrm{O} 4$ reaches the middle position between O1 and O5 with an O1-O4 and O4-O5 distance of $1.946 \AA$ and $1.958 \AA$, respectively. The O1-O4-O5 linkage showed similar geometry and bonding characteristics to those in $\left(\mathrm{Li}_{2} \mathrm{CO}_{3}\right)_{4}$ and $\left(\mathrm{Na}_{2} \mathrm{CO}_{3}\right)_{4}$. The reaction path is confirmed by the IRC calculations. The energy barrier is calculated to be $128.1 \mathrm{~kJ} / \mathrm{mol}$, comparable to the previous values in $\left(\mathrm{Li}_{2} \mathrm{CO}_{3}\right)_{4}$ and $\left(\mathrm{Na}_{2} \mathrm{CO}_{3}\right)_{4}$.

\subsection{Mechanism of oxygen migration in molten carbonate}

To illustrate the mechanism and energetics of oxygen migration in different molten carbonate salts, accuracy and reliability of calculated energies are the key and of great importance. Both the structures of trasition state and $\mathrm{CO}_{4}{ }^{2-}$ are ozone-like, so they may have considerable biradical character [35-38]. The results from the B3LYP/6-31G(d) will need to be verified by higher level of theoretical methods. Therefore, single point energy calculations were performed in the current study using MP4 and $\operatorname{CCSD}(\mathrm{T})$ with combination of a variety of basis sets including $6-31 \mathrm{G}(\mathrm{d})$, 6-311G++(d), CBSB7 and LANL2DZ. All calculated values are listed in Table 1. Three corrections were considered and calculated. The ZPE correction ranges from -2.2 -4.6 kJ/mol, which lowers the activation energy by about $2.2 \sim 3.4 \%$. To assure the reliability of basis set, three basis sets including 6-31G(d), 6-311G++(d) and CBSB7 were tested. It was found that the increase of basis set slightly decreases the energy barrer. The change is only $-2.7,-1.3$ and -6.1 
$\mathrm{kJ} / \mathrm{mol}$ for $\left(\mathrm{Li}_{2} \mathrm{CO}_{3}\right)_{4},\left(\mathrm{Na}_{2} \mathrm{CO}_{3}\right)_{4}$ and $\left(\mathrm{K}_{2} \mathrm{CO}_{3}\right)_{4}$, respectively. Using LANL2DZ, the energy barrier was calibrated at the level of MP4 and $\operatorname{CCSD}(\mathrm{T})$. In MP4 and $\operatorname{CCSD}(\mathrm{T})$, the energy barrier was increased by $12-17 \%$ and $4-7 \%$, respectively. Considering the formation of the O1-O4-O5 linkage in the structure of TS and that the middle oxygen may have partial biradical character, $\operatorname{CCSD}(\mathrm{T})$ should provide a better estimate than MP4 does. It is noticible that the results from $\operatorname{CCSD}(\mathrm{T})$ and B3LYP agree very well, indicating that the B3LYP/6-31G(d) method is fairly reliable and accurate in the current study.

For intermolecular migration of oxygen in molten carbonate, the energy barrier is calculated to be $103.0,136.3$ and $127.9 \mathrm{~kJ} / \mathrm{mol}$ in lithium, sodium and potasium carbonate, respectively. Molten lithium carbonate is not only favored by the kinetics of oxygen migration, but also it can lower the melting temperature of MC. So it is widely used with sodium and potassium carbonate slats. In terms of sodium or potassium molten carbonate, the calculated energy barriers are very close with sodinum slightly higher. For the inter-carbonate migration of oxygen in MC, the energy barrier is significantly lower than that of the intra-carbonate path. $\mathrm{For}_{\mathrm{CO}_{4}}{ }^{2-}$ in the molten carbonate salt as shown in Fig. 5, 7 and 8, the O1-O4 distance is 1.465-1.480 ̊, while the total Mulliken charge on O1-O4 is $-0.77-0.85$ e. The O1-O4 stretching frequency is about $900 \mathrm{~cm}^{-1}$. The change of geometry, charge and frequency from $\mathrm{Li}, \mathrm{Na}$ to $\mathrm{K}$ salt is neligible. From the aspect of $\mathrm{O} 1-\mathrm{O} 4$ distance and stretching, $\mathrm{O} 1-\mathrm{O} 4$ is similar to peroxide with both $\pi_{2 \mathrm{p}}$ bonding and $\pi_{2 \mathrm{p}}$ antibonding orbitals occupied through molecular orbital analysis. Once O1-O4 is elongated, the $\sigma_{2 p-2 p}$ bond is being broken, which will release the $2 \mathrm{p}$ orbital of $\mathrm{O} 4$ and make it ready for a new bond with $\mathrm{O} 5$ as shown in Fig. 6. A linkage of O1-O4-O5 is then formed, which is also strengthened by a $\pi_{2 \mathrm{p}}$ orbital (Fig. 6, right). The formation of such a $\mathrm{O} \cdots \mathrm{O} \cdots \mathrm{O}$ linkage supports the cogwheel mechanism as previously proposed [15].

It is well known that the process of ORR in the cathode is extremely important in the oxide conducting SOFCs. This reacton involes the adsorption and dissociation of oxygen, the diffusion of oxygen, and the reduction of oxygen by two electrons on the surface of cathode. Of these steps, the migration rate of oxygen is as equally important as the others and has significant effects on the kinetics of ORR and the cell performance. As seen from Fig.1, the surface area for ORR is largely increased with the presence of MC. In particlular, molten carbonate salts at TPB will provide alternative channels for the migration of oxygen from cathode to electrolyte. The ORR will no 
more be limited to TPB and the cathode kinetics will be largely improved, resulting in better cell performance.

\section{Conclusions}

We have reported a DFT study of oxygen migration in selected molten carbonate salts. The geometries were optimized at the B3LYP/6-31G(d) level and single point energy corrections were performed using MP4 and $\operatorname{CCSD}(\mathrm{T})$. At TS, a O-O-O linkage is formed and O-O bond forming and breaking is concerted. A cooperative "cogwheel" mechanism as described in the equation of $\mathrm{CO}_{4}{ }^{2-}+\mathrm{CO}_{3}{ }^{2-} \rightarrow \mathrm{CO}_{3}{ }^{2-} \cdots \mathrm{O} \cdots \mathrm{CO}_{3}{ }^{2-} \rightarrow \mathrm{CO}_{3}{ }^{2-}+\mathrm{CO}_{4}{ }^{2-}$ is proposed. The energy barrier is calculated to be $103.0,136.3$ and $127.9 \mathrm{~kJ} / \mathrm{mol}$ through an intra-carbonate pathway in lithium, sodium and potasium carbonate, respectively. The reliability and accuracy of B3LYP/6-31G(d) were verifed by $\operatorname{CCSD}(\mathrm{T})$. The calculated low values of activation energy indicate that the oxygen transfer in molten carbonate salts is fairly easy. In addition, it is found that lithium carbonate is not only a favorable molten carbonate salt for better cathode kinetics, but also it is widely used for reducing the melting point of $\mathrm{Li} / \mathrm{Na}$ and $\mathrm{Li} / \mathrm{K}$ eutectic mixtures in experiments. The current results imply that the process of oxygen reduction in MC modified cathodes is facilitated by the presence of MC, resulting in an enhancement of cell performance at low operating temperatures.

\section{Acknowledgements}

The authors gratefully acknowledge the Army Research Office (ARO) of the Department of Defense (DoD) (Grant Number: 59047CHREP and 62940CHREP) for financial support of this work. We also thank the National Science Foundation (Grant Number: CBET-1340269 and CBET-1264706 ) for partial support.

\section{References}

[1] B. C. Steele and A. Heinzel, Nature 414 (2001) 345.

[2] Y. Zhao, C. Xia, L. Jia, Z. Wang, H. Li, J. Yu, Y. Li, Int. J. Hydrogen Energy 38 (2013) 16 $498-16517$.

[3] X. Wang, Y. Ma, B. Zhu, Int. J. Hydrogen Energy 37 (2012) 19417-19425.

[4] C. Xia, L. Li, Y. Tian, Q. Liu, Y. Zhao, L. Jia, Y. Li, J. Power Sources 188 (2009) 156-162.

[5] C. Xia, L. Li, Y. Tian, Q. Liu, Z. Wang, L. Jia, Y. Zhao, Y. Li, J. Power Sources 195 (2010) $3149-3154$. 
[6] B. Zhu, B. E. Mellander, Solid State Phenom. 39-40 (1994) 19-22.

[7] B. Zhu, X. Liu, P. Zhou, X. Yang, Z. Zhu, W. Zhu, Electrochem. Commun. 3 (2001) 566-571.

[8] J. Di, M. Chen, C. Wang, J. Zheng, L. Fan, B. Zhu, J. Power Sources 195 (2010) 4695-4699.

[9] X. Li, N. Xu, L. Zhang, K. Huang, Electrochem. Commun. 13 (2011) 694-697.

[10] L. Zhang, X. Li, S. Wang, K. G. Romito, K. Huang, Electrochem. Commun. 13 (2011) $554-557$.

[11] Y. Gong, X. Li, L. Zhang, W. Tharp, C. Qin, and K. Huang, J. Electrochem. Soc. 161 (2014) F226-F232.

[12] A. Bodén, J. Di, C. Lagergren, G. Lindbergh, C. Y. Wang, J. Power Sources 172 (2007) $520-529$.

[13] F. Xie, C. Wang, Z. Mao, Z. Zhan, Int. J. Hydrogen Energy 39 (2014) 14397-14401.

[14] S. Shawuti, M. A. Gulgun, J. Power Sources 267 (2014) 128-135.

[15] Y. Gong, X. Li, L. Zhang, W. Tharp, C. Qin, and K. Huang, J. Electrochem. Soc. 160 (2013) (9) F958-F964.

[16] C. Qin, A. Gladney, Comput. Theor. Chem. 999 (2012) 179-183.

[17] L. J. Chen, C. J. Lin, J. Zuo, L. C. Song, and C. M. Huang, J. Phys. Chem. B. 108 (2004) 7553.

[18] X. Lei, K. Haines, K. Huang, C. Qin, J. Phys. Chem. A 119(33) (2015) 8806-8812.

[19] M. J. Frisch, G. W. Trucks, H. B. Schlegel, G. E. Scuseria, M. A. Robb, J. R. Cheeseman, J. J. A. Montgomery, T. Vreven, K. N. Kudin, J. C. Burant, et al., Gaussian g09, Revision B. 01, Inc., Wallingford CT, 2010.

[20] C. Lee, W. Yang, R.G. Parr, Phys. Rev. B 37 (1988) 785-789.

[21] A. D. Becke, 98 (1993) 5648-5652.

[22] M. M. Francl, W. J. Pietro, W. J. Hehre, J. S. Binkley, D. J. DeFrees, J. A. Pople and M. S. Gordon, J. Chem. Phys. 77 (1982) 3654-3665.

[23] J. P. Blaudeau, M. P. McGrath, L. A. Curtiss and L. Radom, J. Chem. Phys. 107 (1997) 5016-5021.

[24] V. A. Rassolov, J. A. Pople, M. A. Ratner and T. L. Windus, J. Chem. Phys. 109 (1998) 1223-1229.

[25] V. A. Rassolov, M. A. Ratner, J. A. Pople, P. C. Redfern and L. A. Curtiss, J. Comp. Chem. 22 
(2001) 976-984.

[26] K. Raghavachari and J. A. Pople, Int. J. Quantum Chem. 14 (1978) 91-100.

[27] G. E. Scuseria, C. L. Janssen and III H. F. Schaefer, J. Chem. Phys. 89 (1988) 7382-7387.

[28] J. A. Pople, M. Head-Gordon and K. Raghavachari, J. Chem. Phys. 87 (1987) 5968-5975.

[29] A. D. McLean, G. S. Chandler, J. Chem. Phys. 72 (1980) 5639-5648.

[30] K. Raghavachari, J. S. Binkley, R. Seeger, J. A. Pople, J. Chem. Phys. 72 (1980) 650-654.

[31] T. Clark, J. Chandrasekhar, G. W. Spitznagel, P. V. R. Schleyer, J. Comput. Chem. 4 (1983) 294-301.

[32] J. J. A. Montgomery, M. J. Frisch, J. W. Ochterski and G. A. A. Petersson, J. Chem. Phys. 110 (1999) 2822-2827.

[33] W. R. Wadt and P. J. Hay, J. Chem. Phys. 82 (1985) 284-298.

[34] P. J. Hay and W. R. Wadt, J. Chem. Phys. 82 (1985) 299-310.

[35] J. Kalinowski, P. Heinonen, I. Kilpeläinen, M. Räsänen, and R. B. Gerber, J. Phys. Chem. A 119 (2015) 2318-2325.

[36] D. Cremer, J. Am. Chem. Soc. 101 (1979) 7199-7205.

[37] D. Cremer, J. Gauss, E. Kraka, J. F. Stanton, R. J. Bartlett, Chem. Phys. Lett. 209 (1993) $547-556$.

[38] E. Miliordos, K. Ruedenberg, S. S. Xantheas, Angew. Chem. 125 (2013) 5848-5851. 
Table 1. The activation energy $(\mathrm{kJ} / \mathrm{mol})$ of oxygen migration in $\left(\mathrm{M}_{2} \mathrm{CO}_{3}\right)_{4}(\mathrm{M}=\mathrm{Li}, \mathrm{Na}, \mathrm{K})$ calculated by B3LYP/6-31G(d), B3LYP/6-311++G(d), B3LYP/CBSB7, B3LYP/LANL2DZ, MP4/LANL2DZ, and CCSD(T)/LANL2DZ.

\begin{tabular}{|c|c|c|c|c|c|c|c|c|c|c|}
\hline \multirow{3}{*}{ Cluster } & \multicolumn{3}{|c|}{ B3LYP } & B3LYP & MP4 & $\operatorname{CCSD}(T)$ & \multicolumn{3}{|c|}{ Correction } & \multirow{3}{*}{$\begin{array}{l}\mathbf{E a}^{\mathbf{d}} \\
103.0\end{array}$} \\
\hline & 6-31G(d) & 6-311++G(d) & CBSB7 & \multicolumn{3}{|c|}{ LANL2DZ } & $\mathrm{ZPE}^{\mathrm{a}}$ & $\Delta \mathbf{E}^{\mathbf{b}}$ & $\Delta \mathbf{E}^{\mathrm{c}}$ & \\
\hline & 104.3 & 102.3 & 101.6 & 86.8 & 97.4 & 90.4 & -2.2 & -2.7 & +3.6 & \\
\hline $\mathrm{O}-\left(\mathrm{Na}_{2} \mathrm{CO}_{3}\right)_{4}$ & 136.0 & 122.2 & 134.7 & 104.6 & 119.7 & 110.8 & -4.6 & -1.3 & +6.2 & 136.3 \\
\hline $\mathrm{O}-\left(\mathrm{K}_{2} \mathrm{CO}_{3}\right)_{4}$ & 129.7 & 125.5 & 123.6 & 103.8 & 121.3 & 112.4 & -3.3 & -6.1 & +8.6 & 127.9 \\
\hline
\end{tabular}

a -ZPE correction at the B3LYP/6-31G(d) level

b -Correction energy $\Delta \mathrm{E}=\mathrm{E}_{\mathrm{B} 3 \mathrm{LYP} / \mathrm{CBSB} 7}-\mathrm{E}_{\mathrm{B} 3 \mathrm{LYP} / 6-31 \mathrm{G}(\mathrm{d})}$

c -Correction energy $\Delta \mathrm{E}=\mathrm{E}_{\mathrm{CCSD}(\mathrm{T}) / \mathrm{LANL2DZ}}-\mathrm{E}_{\mathrm{B} 3 \mathrm{LYP} / \mathrm{LANL2DZ}}$

$\mathrm{d}$-Activation energy with corrections $\quad \mathrm{Ea}=\mathrm{E}_{\mathrm{B} 3 \mathrm{LYP} / 6-31 \mathrm{G}(\mathrm{d})}+\mathrm{ZPE}^{\mathrm{a}}+\Delta \mathrm{E}^{\mathrm{b}}+\Delta \mathrm{E}^{\mathrm{c}}$ 


\section{Figure Captions}

Fig. 1 Illustration of oxygen reduction reaction in SOFCs (Left: No MC, Right: With MC).

Fig. 2 Optimized structures of $\left(\mathrm{M}_{2} \mathrm{CO}_{3}\right)_{4}(\mathrm{M}=\mathrm{Li}, \mathrm{Na}, \mathrm{K})$ at the B3LYP/6-31G (d) level.

Fig. 3 The structures of reactant, transitioning state (TS) and product, as well as the relative energy (kJ/mol) for intramolecular transfer of oxygen in carbonate ion. (Distance in $\AA$; gray and red balls represent $\mathrm{C}$ and $\mathrm{O}$, respectively.)

Fig. 4 Selected molecular orbitals related to the bonding of O5-O4 and O5-O2 at TS.

Fig. 5 The structures of reactant, transitioning state (TS) and product, as well as the relative energy (in $\mathrm{kJ} / \mathrm{mol}$ ) for oxygen migration in lithium carbonate $\left(\mathrm{Li}_{2} \mathrm{CO}_{3}\right)_{4}$. (Distance in $\AA$; gray, red, and purple balls represent $\mathrm{C}, \mathrm{O}$, and $\mathrm{Li}$, respectively).

Fig. 6 Selected molecular orbitals related to the bonding of O1-O4-O5 at TS.

Fig. 7 The structures of reactant, transitioning state (TS) and product, as well as the relative energy for oxygen migration in the sodium carbonate cluster $\left(\mathrm{Na}_{2} \mathrm{CO}_{3}\right)_{4}$. (Distance in $\AA$; gray, red, and purple balls represent $\mathrm{C}, \mathrm{O}$, and $\mathrm{Na}$, respectively).

Fig. 8 The structures of reactant, transitioning state (TS) and product, as well as the relative energy for oxygen migration in the potassium carbonate cluster $\left(\mathrm{K}_{2} \mathrm{CO}_{3}\right)_{4}$. (Distance in $\AA$; gray, red, and purple balls represents $\mathrm{C}, \mathrm{O}$, and $\mathrm{K}$, respectively) 


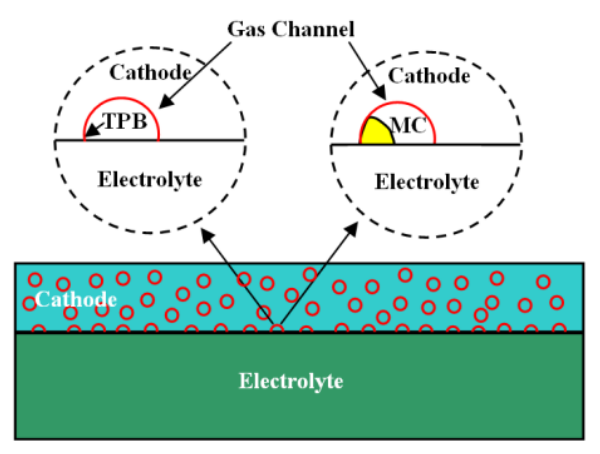

Fig. 1

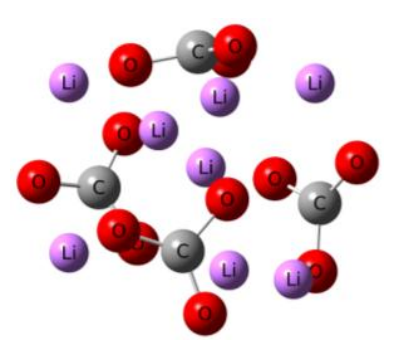

$\left(\mathrm{Li}_{2} \mathrm{CO}_{3}\right)_{4}$

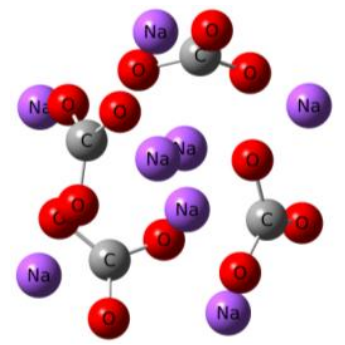

$\left(\mathrm{Na}_{2} \mathrm{CO}_{3}\right)_{4}$

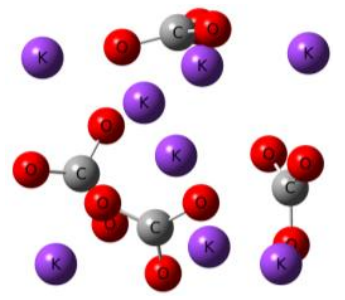

$\left(\mathrm{K}_{2} \mathrm{CO}_{3}\right)_{4}$

Fig. 2

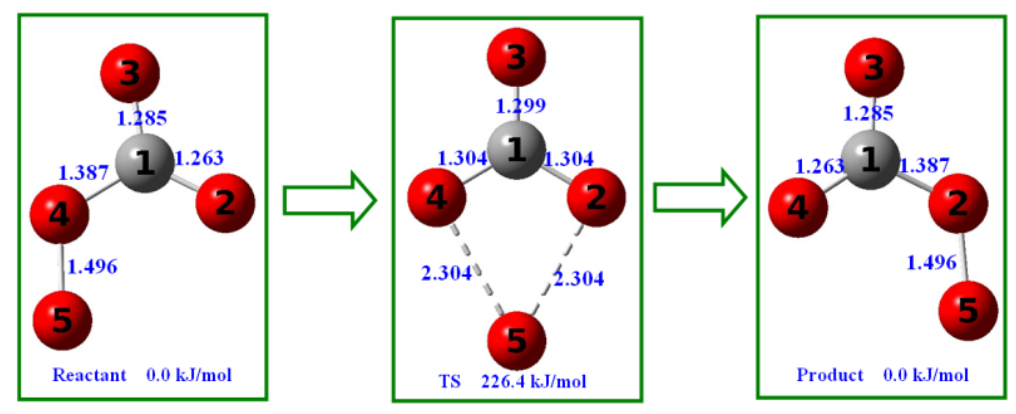

Fig. 3 

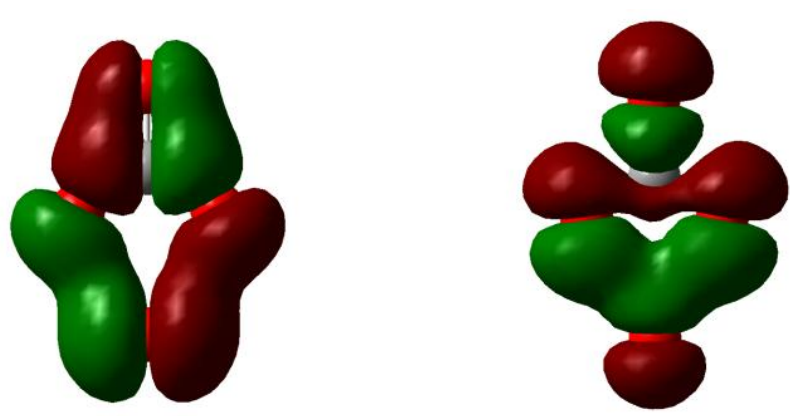

Fig. 4

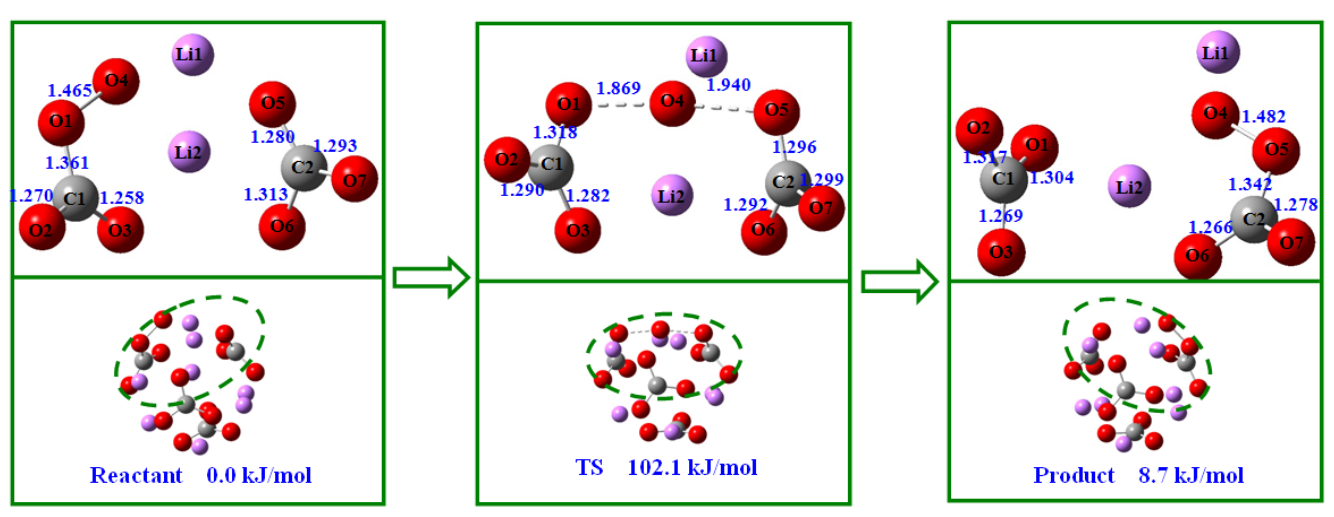

Fig. 5
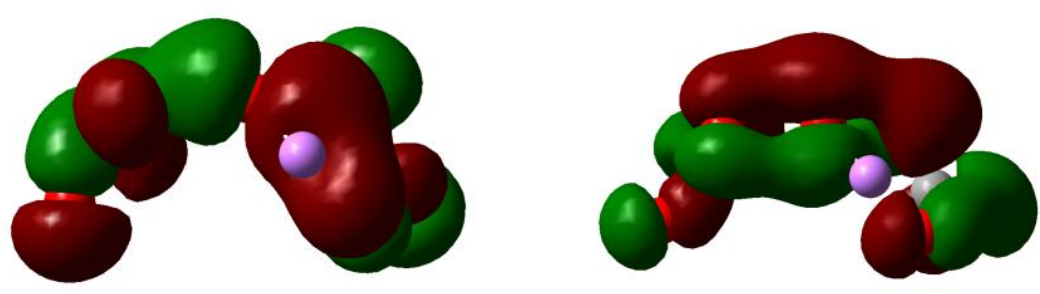

Fig. 6 


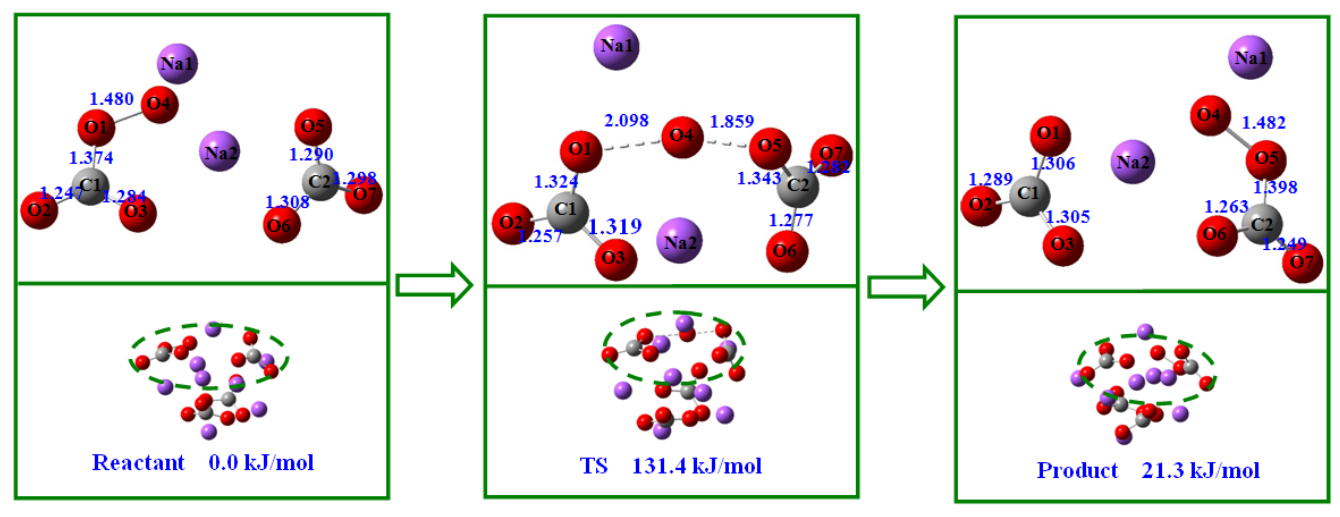

Fig. 7

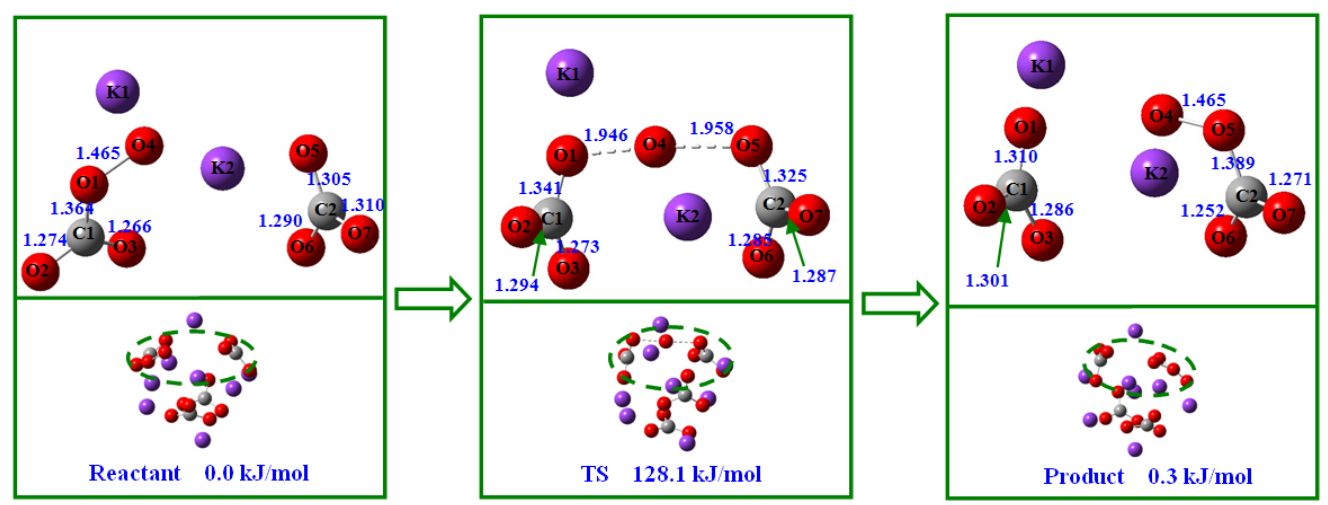

Fig. 8 


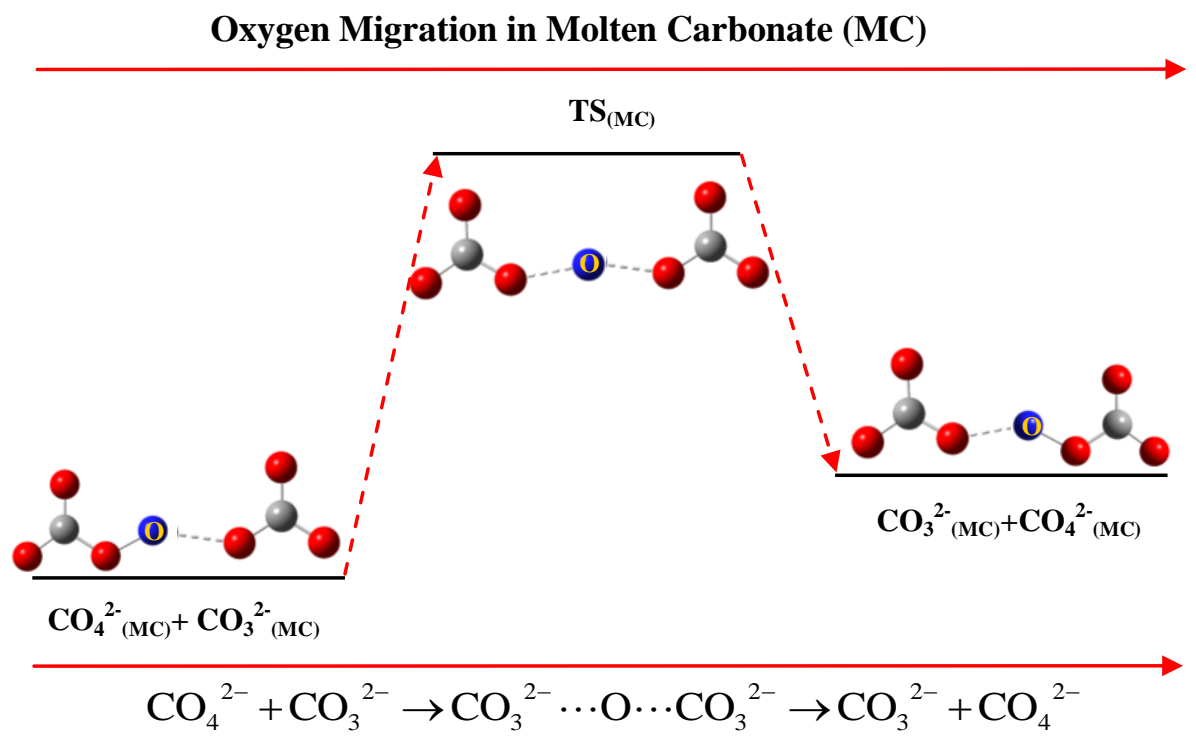

